\title{
Mechanical and electrochemical behaviour of aluminum-based hybrid composites reinforced with silicon carbide and pride of barbardos seed ash produced by stir casting
}

\begin{abstract}
Aluminum matrix composite (AMCs) represent a class of MMCs with low density, high stiffness and strength, superior wear resistance, controlled co-efficient of thermal expansion, high fatigue resistance and better stability at elevated temperature. These properties made AMCs a good candidate for the design of a wide range of components for advanced applications. This research focus on mechanical and electrochemical behavior of developed Aluminum 6063 hybrid composites containing 0:10, 2.5:7.5, 5:5, 7.5:2.5 and 10:0 wt.\% pride of Barbados seed ash (PBSA) and silicon carbide (SiC) as reinforcements. Different characterization techniques were used to evaluate the mechanical behavior. Similarly, electrochemical studies were carried out using potentio-dynamic polarization technique at room temperature. The results show that the yield strength, ultimate tensile strength and percentage elongation of the hybrid composites increase with increase in PBSA content while the hardness is decreased. Electrochemical test revealed that hybrid $\mathrm{Al} / 2,5 \mathrm{wt}$. \% PBSA had superior corrosion resistance.
\end{abstract}

Keywords: composite, matrix, pride of barbados, hardness, hybrid, polarization potential, current density
Volume 3 Issue 5 - 2019

\author{
Olaniran Oladayo, ${ }^{1,2}$ Alege Kehinde Sikirat' \\ 'Department of Metallurgical and Materials Engineering, Federal \\ University of Technology, Nigeria \\ ${ }^{2}$ Department of Chemical Engineering, Texas Tech University, \\ USA
}

Correspondence: Olaniran Oladayo, Department of Metallurgical and Materials Engineering, Federal University of Technology, P.M.B 704, Nigeria, Tel 2348035001939 ,

Email oladayolaniran@gmail.com

Received: September 27, 2019| Published: October 18, 2019
Abbreviations: AMCs, aluminum matrix composite; PBSA, pride of barbados seed ash; HAMCSs, hybrid aluminum metal composites

\section{Introduction}

Aluminum matrix composite (AMCs) represent a class of MMCs having characteristics of low density, high stiffness and strength, superior wear resistance, controlled co-efficient of thermal expansion, high fatigue resistance and better stability at elevated temperature. These properties made AMCs a good candidate for the design of various components for advanced engineering applications. ${ }^{1}$ It has been found that the use of AMCs in engine applications can reduce the overall weight, fuel consumption and pollution in the automobiles and aircrafts. ${ }^{2}$ MMCs reinforced with ceramic particles are very promising materials for structural applications due to excellent combination of properties. ${ }^{3}$ AMCs reinforced with either silicon carbide $\left(3.18 \mathrm{~g} / \mathrm{cm}^{3}\right)$ or alumina $\left(3.9 \mathrm{~g} / \mathrm{cm}^{3}\right)$ particles are attractive materials for aviation. ${ }^{4,5}$ Some of the reinforcements are denser than aluminum alloys $\left(2.7 \mathrm{~g} / \mathrm{cm}^{3}\right)$ and therefore increase the weight of the composites produced depending on the quantity of the reinforcement added. ${ }^{6}$ Moreover, ceramic particles addition to the Al-alloy increases the hardness and thereby making machining more difficult. ${ }^{6}$ Hybrid composites, in most cases possess superior strength than monolithic composite. The properties of the hybrid reinforcements (primary and secondary) can be combined to attain better material properties. More so, the use of stir casting method for production of AMCs reduces the cost of the composite. ${ }^{7}$ Current trends in AMCs show growing concern in the production of hybrid Aluminum Metal Composites
(HAMCSs) with better physical and mechanical properties. Resent researches have shown that agro/industrial waste materials such as fly ash, graphite, rice husk ash, amongst others, can be successfully used as a complementary reinforcement in AMCs. ${ }^{7,8}$ Furthermore, the use of hybrid reinforcements increases the service performance of the composites by the formation of new features. These agro/industrial wastes can reduce the cost of aluminum composites. Secondly, the weight of the composite can be manipulated due to lower density of this agro/industrial waste materials. ${ }^{3}$ Thirdly, these composites can also offer competitive physical and mechanical properties. ${ }^{7}$ This research investigates the mechanical and corrosion behavior of Aluminum-hybrid composite produced by reinforcing Aluminum 6063 with pride of Barbados seed ash and silicon carbide via double stir casting method.

\section{Materials and method}

Aluminum 6063 served as the matrix of the composite. Pure silicon carbide $(\mathrm{SiC})$ particles having average particle size of $30 \mu \mathrm{m}$ and pride of barbardos seed ash (PBA) were used as reinforcements for the hybrid composites. Dried pride of barbardos seeds were gathered and placed in a metallic drum and fired in open air to allow for thorough combustion. The ash produced from the burning process was allowed to cool for 24 hours after which it was removed from the drum. The ash was then conditioned in a furnace at a temperature of $65^{\circ} \mathrm{C}$ for 3 hours. The ash seeds were further ground using ball mill and sieved with a sieve shaker to obtain ashes with mesh size under $73 \mu \mathrm{m}$. Two steps stir casting process was used for the development of the composites. Charge calculation was used to determine the quantity of 
pride of barbardos seed ash (PBSA) and silicon carbide $(\mathrm{SiC})$ required to prepare $10 \mathrm{w} . \%$ reinforcement (in the $\mathrm{Al}$ matrix) consisting of $0: 10$, 2.5:7.5, 5:5, 7.5:2.5 and 10:0 pride of barbardos seed ash (PBSA and silicon carbide weight percent respectively. The PBSA and silicon carbide particles were initially preheated individually at $250^{\circ} \mathrm{C}$ to remove moisture and also helps improve wettability with the molten aluminum 6063 . The aluminum 6063 billets were charged into a gasfired crucible furnace (fitted with a temperature probe), and heated to temperature of $750^{\circ} \mathrm{C}$ (above the liquid us temperature of the alloy) to ensure complete melting of the alloy. The liquid alloy is then allowed to cool in the furnace to a semi solid state (slurry) at temperature of about $600^{\circ} \mathrm{C}$. The preheated PBSA and SiC particles were then introduced into the melt at this temperature and stirring of the slurry was done manually for 5-10 minutes. The slurry was then superheated to $800^{\circ} \mathrm{C}$ and second stirring performed using a mechanical stirrer. This stirring procedure was done at a speed of $400 \mathrm{rpm}$ for a total of 10 minutes before casting into prepared sand moulds inserted with chills.

\section{Material test}

Mechanical and electrochemical tests were carried out on the developed hybrid composites.

\section{Wear test}

The wear resistance was evaluated using the Taber wear index. A $10 \mathrm{~mm}$ thick circular disc sample with a $0.6 \mathrm{~mm}$ hole drilled at the center was subjected to wear test on a Taber rotary platform abrader for a total time of 15 minutes. The initial weight of the samples were taken prior to wear test, the samples were then cleaned and weighed after the test to record the weight of the abraded sample. The Taber index was determined using the equation below.

$$
W=\frac{B-A}{400} X 1000
$$

Where $\mathrm{W}$ is the wear Index, $\mathrm{A}$ and $\mathrm{B}$ are the weight (Mass) before and after abrasion while 400 is the number of test cycles (revolution per minutes).

\section{Tensile test}

Tensile tests were performed on the developed hybrid composites with the specifications of ASTM 8M-91 standard. The samples for the test were machined to round specimen configuration with $6 \mathrm{~mm}$ diameter and $30 \mathrm{~mm}$ gauge length. The test was carried out at room temperature using an Instron universal testing machine operated at a strain rate of $10 \mathrm{~m} / \mathrm{s}$. Three repeats tests were performed and average value was taken to guarantee reliability of the generated data. The tensile properties evaluated were from the stress-strain curves. The properties are ultimate tensile strength $(\sigma u), 0.2 \%$ offset yield strength $(\sigma y)$, and strain to fracture $(\varepsilon f)$.

\section{Hardness test}

The hardness of the composites was evaluated using INDENTEC Micro-hardness Tester 2015 Model. Prior to testing, a flat and smooth surface samples were prepared from each develop composite composition. A load of 100 gf was applied on the samples and the hardness profile was deduced following standard procedures. Multiple hardness tests were performed on each sample and the average value recorded as a measure of the hardness of the sample.

\section{Electrochemical test}

Electrochemical study was carried out on the hybrid composites using ASTM-G5 standard (2011). ${ }^{9}$ The surfaces of the samples were ground, polished and washed with distilled water, degreased in acetone and finally dried in air. The electrochemical property of these hybrid composites were studied using Princeton Autolab Potentiostat (Model PGSTAT 204N computer controlled) and the data were analyzed by the general purpose electrochemical Nova software (GPES) version 49. The set up was done using 3.0 \% $\mathrm{NaCl}$ solution at room temperature. The polarization curves were measured at a scan rate of $0.25 \mathrm{mV} / \mathrm{s}$. The pitting potential was determined as the potential at which the current density exceeded $100 \mu \mathrm{A} / \mathrm{cm}^{2}$ and stable for more than 1 minute. The electrolyte was replaced after each scan.

\section{Results and discussion}

Table 1 shows multiple hardness values of different hybrid composition with their average hardness values. The result revealed that the hardness value of the unreinforced composite (control sample) was higher than both single reinforced and hybrid composites. In addition, the single reinforced $\mathrm{Al} / \mathrm{SiC}$ composite has higher hardness values than the hybrid. The hardness of the hybrid composites decreases with increasing wt. \% pride of Barbados seed ash. This observation was favorable with what has been reported on Al-MgSi reinforced with other agro-waste ash (BLA and RHA) $;{ }^{7}$ reported that the hardness of the composites reduces with increasing RHA content in $\mathrm{Al}-\mathrm{Mg}-\mathrm{Si} / \mathrm{Al}_{2} \mathrm{O}_{3}$ RHA composites. This reduction could be attributed to the low hardness of silica (the main constituent of the ashes) in comparison with synthetic reinforcements $\mathrm{SiC}$ and $\mathrm{Al}$ 6063). This low value of hardness is favorable for improving machinability. ${ }^{10}$ The Al/10 wt. \% PBSA (sample 4) has a higher hardness value compared with $\mathrm{Al} / 10$ wt. \% $\mathrm{SiC}$ (sample 1) for the single reinforced composite and the developed hybrid reinforced composites. The developed hybrid reinforced composite $\mathrm{Al} / 2.5$ wt.\% $\mathrm{SiC} / 7.5$ wt. $\%$ PBSA (sample 4) showed a higher hardness resistance while compare to other developed hybrid reinforced composites.

Table I Average hardness value of the aluminum 6063, single reinforced composites (Al/SiC and Al/PBSA) and aluminum hybrid composite (Al/SiC/PBSA)

\begin{tabular}{llllll}
\hline Composition & Hvl & Hv2 & Hv3 & Hv4 & Average Hv \\
\hline AL alloy & 46 & 44.5 & 46.1 & 43.7 & 45.075 \\
AL/10 0wt.\% SiC & 44.5 & 45.5 & 46.1 & 43 & 44.775 \\
AL/7.5 wt.\% SiC/2.5 wt.\% PBA & 45.8 & 44.8 & 44.3 & 42.4 & 44.325 \\
AL/50 wt.\% SiC/50 wt.\% PBA & 45.9 & 43 & 44 & 44 & 44.225 \\
AL/2.5wt.\% SiC/7.5 wt.\% PBA & 37.8 & 42 & 44.3 & 42.3 & 41.6 \\
AL/10 wt.\% PBA & 40.97 & 40.97 & 40.97 & 40.97 & 40.97 \\
\hline
\end{tabular}


Table 2 shows the wear index values of the Aluminum 6063 , single reinforced composites ( $\mathrm{Al} / \mathrm{Sc}$ and $\mathrm{Al} / \mathrm{PBSA})$ and the developed Aluminum Hybrid composite. It was observed that the wear index of the unreinforced composite (control sample) was higher than both single reinforced and hybrid composite. Likewise, the single reinforced $\mathrm{Al} / \mathrm{SiC}$ composite (sample 1) has higher wear rate than the single reinforces $\mathrm{Al} / \mathrm{PBSA}$ and the developed hybrid composites, as expected. It was observed that samples, 4 and 5, containing PBSA have a wear rate close to that of single reinforced composite (Al/PBSA). It was also seen that wear rate of the developed hybrid composites decreases with increasing wt. \% of PBSA. It was expected that the single reinforced composite (sample 1) should have highest wear rate because of the highest hardness value it possesses. The single reinforced composite (sample 5) was observed to have a superior wear resistance while compared to developed reinforced hybrid composites (samples 2 - 4). In relationship with hardness values, it could be deduced that decrease in hardness led to reduction in the wear rate of the hybrid composite. This result was in agreement with ${ }^{11}$ where $\mathrm{Al}$ (A356.2) alloy composite was reinforced with rice husk ash (RHA). From Figure 1, it was observed that the ultimate tensile strength (UTS) of the unreinforced sample (control sample) was higher than sample 2 and equal in value with sample 4 . The single reinforced composites $(\mathrm{Al} / \mathrm{SiC}$ and $\mathrm{Al} / \mathrm{PBSA})$ also revealed an improvement in the UTS than the unreinforced sample. Likewise, the UTS of Al/ PBSA was higher than $\mathrm{Al} / \mathrm{SiC}$. The UTS of the hybrid composites increases with percentage increase in PBSA. However, there was a sudden drop in UTS at sample 4. This may be due to uneven/non uniform distribution of the reinforcement during casting. ${ }^{11}$ Results of yield strength of Aluminum 6063 single reinforced composites ( $\mathrm{Al} / \mathrm{SiC}$ and PBSA) together with the hybrids composites $(\mathrm{Al} / \mathrm{SiC} /$ PBSA) is presented in Figure 2. From the results, it was observed that the yield strength of the unreinforced sample (control sample) was higher than samples 1 and 4 while the single reinforced composites $(\mathrm{Al} / \mathrm{SiC})$ and $\mathrm{Al} / \mathrm{PBSA})$ showed an improvement in the yield strength than the unreinforced sample. Furthermore, it was also seen that the yield strength of $\mathrm{Al} / \mathrm{PBSA}$ is higher than $\mathrm{Al} / \mathrm{SiC}$. The yield strength of the hybrid composites increases as the percentage composition of the PBSA increases. ${ }^{12}$ There was also a sudden increase in the yield strength at sample 5 which may be attributed to inhomogeneous mixture during casting. The recorded improvement could be due to the increasing number of stress concentration points at the poles of the reinforcing particles. This led to decrease in micro-yielding stress with increase in reinforcement's contents. Figure 2 is the result of the \% Elongation of Aluminum 6063, single reinforced composites (Al/SiC and $\mathrm{Al} / \mathrm{PBSA})$ and Aluminum hybrid composites (Al/Sic/ PBSA). The results revealed that the single reinforced composites has higher \% Elongation than unreinforced sample (control sample). It was observed that the \% Elongation increases as the wt. \% of PBSA increases. This result contradicted the report of Prasad et al., which stated that the ultimate tensile strength (UTS) and yield strength (YS) of $\mathrm{Al} / \mathrm{x} \% \mathrm{SiC} / \mathrm{x} \% \mathrm{RHA}$ ( $\mathrm{x}$ ranges from $0-8 \mathrm{~W} . \%$ ) hybrid composite increased with increase in the weight fraction of reinforcements, while the elongation decreased. ${ }^{11}$ However, the improvement in the $\%$ elongation may be attributed to the absence of hard ceramic phase in the composites, which decreases the brittleness of the developed composites.

Table 2 Wear rate of the aluminum 6063, single reinforced composites (Al/SiC and Al/PBSA) and aluminum hybrid composite (Al/SiC/PBSA)

\begin{tabular}{lllll}
\hline Samples & Composition & Initial weight $(\mathbf{g})$ & Final weight $(\mathbf{g})$ & Wear loss $(\mathrm{g})$ \\
\hline Control sample & AL alloy & 15.12 & 14.839 & 0.28 I \\
Sample I & AL/10 0wt.\% SiC & 16.706 & 16.485 & 0.22 I \\
Sample 2 & AL/7.5 wt.\% SiC/2.5 wt.\% PBA & 15.974 & 15.808 & 0.166 \\
Sample 3 & AL/50 wt.\% SiC/50 wt.\% PBA & 14.1 & 13.986 & 0.114 \\
Sample 4 & AL/2.5wt.\% SiC/7.5 wt.\% PBA & 13.078 & 13.035 & 0.093 \\
Sample 5 & AL/10 wt.\% PBA & 14.048 & 13.963 & 0.085 \\
\hline
\end{tabular}

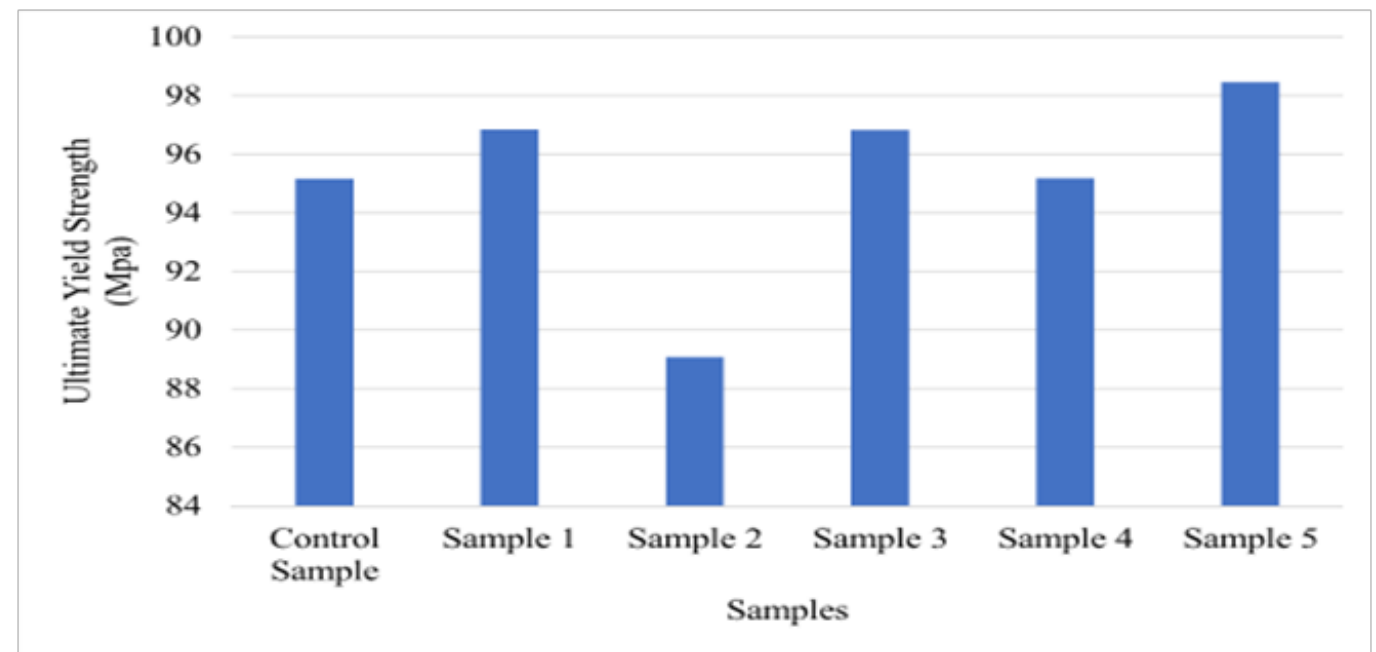

Figure I Variation of Ultimate Tensile Strength and \% elongation of aluminum 6063 , single reinforced composites (Al/SiC and Al/PBSA) and aluminum hybrid composite (Al/SiC/PBSA). 


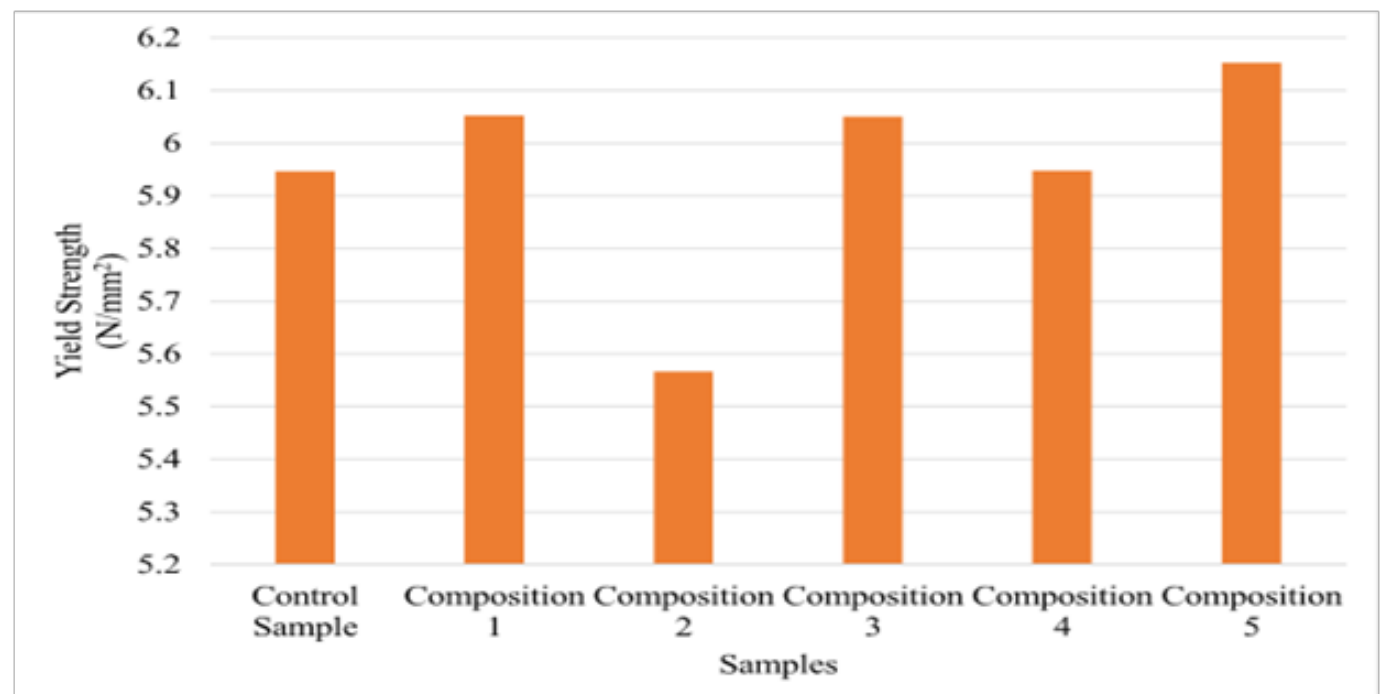

Figure 2 Variation of Yield Strength of aluminum 6063, single reinforced composites (Al/SiC and Al/PBSA) and aluminum hybrid composite (AI/SiC/PBSA).

Table 3 shows the corrosion potentials and corrosion current densities of the Aluminum 6063, single reinforced composites (Al/ $\mathrm{SiC}$ and $\mathrm{Al} / \mathrm{PBSA}$ ) and Aluminum hybrid composite (Al/SiC/PBA) while Figure 3 presents the potentiodynamic polarization curves for Aluminum 6063 and the developed composites. Figure 3 also presents the corrosion potential (Ecorr) and corrosion current density (Icorr). From the data, it was observed that the corrosion potentials (Ecorr) of the composites decreased with increase in PBSA content up to $7.5 \mathrm{wt}$. $\%$ PBSA (samples 2 - 4) and then increased (10wt. \% PBSA). But the corrosion current density (Icorr) increases with increase in PBSA content up to 10wt. \% PBSA. This implies that, the stability of the composites appears to increase with PBSA content up to $7.5 \mathrm{wt} \%$ (as informed by the decreasing corrosion potentials to more positive values with the PBSA content), the corrosion rates actually decreased (from kinetics point of view and judging from the decreasing corrosion current density values) with the PBSA addition. Further addition of PBSA from 7.5 to $10 \mathrm{wt}$. \% (samples 4 and 5) made the composite more susceptible to corrosion by decreasing the corrosion potential below that of other three composites. It also decreased the corrosion current. This means that both from thermodynamics and kinetics considerations, samples 4 and 5 containing 7.5 and 10 wt. \% PBSA are more susceptible to corrosion than other composites produced. It should be noted that although increasing PBSA content from 7.5 to $10 \mathrm{wt}$. \% (samples 4 and 5) increased the susceptibility of the composites to corrosion, it was however observed that it passivated higher than the other composites with highest passivity region in Figure $3 .{ }^{8}$

Table 3 Corrosion potentials and corrosion current densities of aluminum 6063, single reinforced composites (Al/SiC and Al/PBSA) and aluminum hybrid composite (Al/SiC/PBSA)

\begin{tabular}{llll}
\hline Sample & Weight ratio of SiC and PBA & Ecorr $(\mathbf{m V})$ & Icorr $(\boldsymbol{\mu A})$ \\
\hline Control sample & - & -754.574 & -1.704 \\
Sample I & $10: 00$ & -772.613 & -0.935332 \\
Sample 2 & $7.5: 2.5$ & -741.352 & -0.615395 \\
Sample 3 & $5: 05$ & -745.422 & $-0.347 \mid 46$ \\
Sample 4 & $2.5: 7.5$ & -889.764 & $-0.347 \mid 46$ \\
Sample 5 & $0: 10$ & -866.912 & -3.904 \\
\hline
\end{tabular}

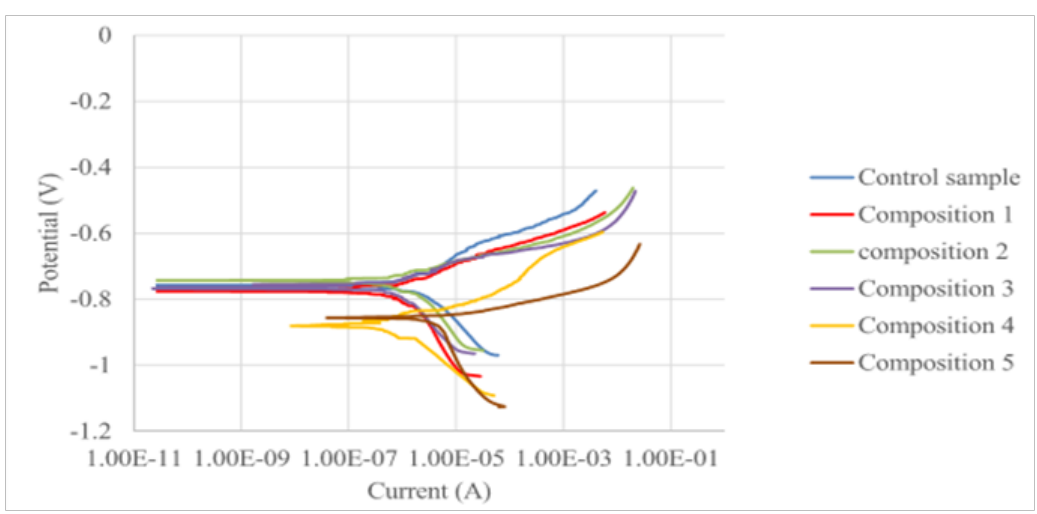

Figure 3 Polarizaion curves of aluminum 6063, single reinforced composites ( $\mathrm{Al} / \mathrm{SiC}$ and $\mathrm{Al} / \mathrm{PBSA}$ ) and aluminum hybrid composite (Al/SiC/PBSA). 


\section{Conclusion}

The mechanical properties and corrosion behavior of Aluminum 6063 matrix composites containing 0:10, 2.5:7.5, 5:5, 7.5:2.5 and 10: 0 wt. \% pride of barbardos seed ash (PBSA) and silicon carbide (SiC) as reinforcements was studied. From the results, it was concluded that:

I. The yield strength, ultimate tensile strength and percentage elongation of the hybrid composites increases with increase in PBSA content while hardness decreased.

II. According to the electrochemical test, it was observed that the samples 2 and 3 containing PBSA hybrid composites had higher corrosion resistance in comparison to the PBSA hybrid (sample 4) and single reinforced Al/PBSA composites. The hybrid reinforced Al/2.5 wt. \% PBSA composite (sample 3) had superior corrosion resistance.

III. Production of low cost Aluminum matrix hybrid composites using PBSA as a complementing reinforcement shows a great promise for hardness, ductility and wears resistance applications judging from the good hardness, ductility and wear properties exhibited by the hybrid containing 5 and 7.5 wt. \% PBSA.

\section{Funding}

None.

\section{Acknowledgements}

None.

\section{Conflicts of interest}

Authors declare that there is no conflict of interest.

\section{References}

1. Surappa MK. Aluminium matrix composites: Challenges and Opportunities. Sadhana. 2003;28(1-2):319-334.
2. Boopathi M, Arulshri KP, Iyandurai N. Evaluation of mechanical properties of aluminium alloy 2024 reinforced with silicon carbide and fly ash hybrid metal marix composites. Am J Appl Sci. 2013;10(3):219-229.

3. Jaswinder S, Amit C. Characerizaion of hybrid aluminium matrix composites for advanced applications $-\mathrm{A}$ review. $J$ mater res technol. 2016;5(2):159-169.

4. Miracle DB. Metal matrix composites- from science to technological significance. Compos Sci Technol. 2005;65:526-540.

5. Gowri SMC, Jayashree PK, Raviraj S, et al. Individual and Combined Effect of Reinforcements on Stir Cast Aluminium Metal Matrix Composites- A Review. Int $J$ of Curr Eng and Tech. 2013;3(3):1-13.

6. Gurcan AB, Baker TN. Wear behavior of Al6061 aluminium alloy and its composites. Wear. 1995; 188:185-191.

7. Alaneme KK, Ademilua BO, Bodunrin MO. Mechanical properties and corrosion behavior of aluminium hybrid composites reinforced with silicon carbide and bamboo leaf ash. Tribol Ind. 2013;35(1):25-35.

8. Alaneme KK, Fatunwase BA, Omotoyinbo JA, et al. Corrosion and wear behavior of stir-cast aluminium-based hybrid composites reinforced with silicon carbide and corn cob ash. Corrosion Institute of Southern Africa. 2015;1(2):1-8

9. ASTM G5-94. Standard Reference Test Method for Making Potentiostatic and Potentiodynamic Anode Polarization Measurement. 2011.

10. Rajmohan T, Palanikumar RS. Evaluation of mechanical and wear properties of hybrid aluminium matrix composites. Trans Non Ferrous Mater Soc China. 2013;23:2509-2517.

11. Prasad DS, Shoba C, Ramanaiahet N. Investigations on mechanical properties of aluminum hybrid composites. J Mater Res Technol. 2013;3(1):79-85.

12. Chawla N, Shen Y. Mechanical behavior of particle reinforced mea matrix Composites. Adv. Eng. Matter. 2001;3(1):357-70. 